\title{
Effect of Conventional and Household Water Treatment Technologies on Pesticide Residues in Drinking Water, Southwestern, Ethiopia
}

Temima Jemal ( $\square$ temimajemal6@gmail.com )

Jimma University College of Public Health and Medical Sciences

Higemengist Astatke

Jimma University College of Public Health and Medical Sciences

Amare Terfe

Arbaminch University, College of Medicine and Health Sciences Sciences and

Seblework Mekonen

Jimma University College of Public Health and Medical Sciences

\section{Research Article}

Keywords: Conventional water treatment, Household treatment, Liquid liquid microextraction, Pesticides, Technologies, Solar Disinfection, Boiling

Posted Date: March 8th, 2022

DOI: https://doi.org/10.21203/rs.3.rs-1372978/v1

License: (c) (i) This work is licensed under a Creative Commons Attribution 4.0 International License. Read Full License 


\section{Abstract}

Water resources have been contaminated by pesticides due to the different activities of human beings. From different studies advanced water treatment systems can eliminate these chemical pesticides while conventional and household treatment technologies are not well studied. The main aim of the present study is to determine the effect of conventional and household water treatment technologies on pesticides residue in drinking water. Water samples were collected from Gibe River (intake point) for Jimma conventional water treatment plant, from each treatment process, and from distribution system. To determine the effect of household water treatment process (solar disinfection and boiling) pesticides were spiked into distilled water then passed through solar disinfection (SODIS) and boiling. The extraction of samples was conducted by following low density based dispersive liquid-liquid micro extraction procedure. The result of the study revealed that almost all studied pesticides ( $p^{\prime} p-D D D, p^{\prime} p$ DDE, p'p-DDT, $y$-Chlordane, dimethachlor, lindane, heptachlor, cypermethrin and deltamethrin) except o'pDDT were detected in water samples. The percent reduction of pesticide residue after post chlorination by conventional water treatment ranges from $11.7 \%$ (p'p-DDD) to $97.29 \%$ (Dimethachlor) and percent reduction of pesticide residue by SODIS and boiling ranges from $2.31 \%$ (o'p-DDT) to $54.45 \%$ (Cypermethrin) and $27.13 \%$ ( $\mathrm{Y}$-Chlordane) to $38.9 \%\left(p^{\prime} \mathrm{p}-\mathrm{DDE}\right)$ respectively. This indicates the treatment technologies are important for the reduction of pesticides in water. Treatment technologies improvement is necessary to allow further removal of pesticides.

\section{Introduction}

Various types of pesticides are widely used in Ethiopian due to agricultural intensifications. Even banned or severely restricted pesticides in other countries like Dichlorodiphenyltrichloroethane (DDT) and others are used illegally. Moreover, much misuse (abuse and overuse) of pesticides is practiced by Ethiopian farmers, particularly when storing, mixing (dosage), and applying them, unwearing protective cloths and disposing of empty containers. These problems can be attributed to farmers' lack of technical knowledge, the absence of extension services, and lack of training on safe pesticide use (Mengistie et al. 2017). Besides their intensive use, pesticides may leach from the irrigation of plants into the ground and surface water sources (Elfikrie et al. 2020). Moreover, only $0.1 \%$ of the pesticides reach the target during application, while the remaining $99.9 \%$ has the potential to move to the different environmental matrices, including surface and groundwater sources (Costa et al. 2018). Pesticide residues were found in drinking water sources around the world including Ethiopia (Elfikrie et al. 2020; Majd et al. 2017; Loha et al. 2020; Mekonen et al. 2016). Profenofos was detected at the highest concentration in the Bulbula River and tap water at the Batu Drinking Water supply in Ethiopia (Loha et al. 2020). In the other study, Diazinon 2, 4-D, Malathion, Fenpropimorph, and Pirimiphos methyl were detected in water samples collected from different drinking water sources at Jimma zone and the study concluded that, there was a decline of pesticide residues concentration from the source (river) to tap water except for Diazinon (Mekonen et al. 2016). Consuming of such polluted water may result in health problem for the humans. Acute exposure to pesticides can lead to serious illness or death. Chronic exposure can impair the function of the 
endocrine, nervous, renal, immune, reproductive, respiratory and cardiovascular systems (Sherpa Awasthi 2019). The chronic effect also include neurotoxic effects, carcinogenic, oncogenic, genotoxic, and teratogenic effects on the human being (Singh et al. 2018). From a study done by (Mekonen et al. 2016) the pesticide residues detected in drinking water have no acute health risk to consumers. However, chronic risks to human health were observed from exposure to some pesticides for Jimma and Addis Ababa populations. Considering the toxicity of pesticides and its metabolites, the removal of pesticides from contaminated aquatic systems is necessary. From different studies, advanced water treatment technologies, such as reverse osmosis, ozonation and advanced oxidation processes, adsorption, and nano filtration, are effective in removing pesticide residues from water (Chelme-Ayala et al. 2011; Thuy et al. 2012; Khoshnood and Azizian 2012; Lin et al. 2012; Moussavi et al. 2013; Zhao et al. 2016; CruzAlcalde et al. 2017). Despite this, advanced water treatment technologies are expensive especially for countries like Ethiopia; however, conventional and household water treatment technologies can be an alternative. Very few studies in other countries showed that conventional water treatment technology has an impact on reducing the levels of pesticides from water (Majd et al. 2017; Elfikrie et al. 2020). However, data were scares with regard to the effect of household water treatment technologies. In most developing countries such as Ethiopia, there is lack of studies conducted on the effect of the both conventional and household water treatment process on pesticide residues. Therefore the main aim of the present study is to determine the level of pesticides from sources, up to point of use and effect of the conventional and household treatment technologies on pesticide residues.

\section{Materials And Methods}

\section{Description of Study area}

The study was conducted in Jimma, southwestern Ethiopia. Jimma is the largest city in southwestern Ethiopia (Fig. 1). It has a latitude and longitude of $\left(7^{\circ} 40^{\prime} \mathrm{N} 36^{\circ} 50^{\prime} \mathrm{E}\right)$ and is located at $350 \mathrm{~km}$ southwest of Addis Ababa at an average altitude of $1780 \mathrm{~m}$ above sea level. One of the sampling areas was the Jimma town's drinking water treatment plant. Gilgel Gibe River is the source of raw water for the Jimma town water treatment plant. The treatment plant has an intake structure with four low-lift pumps and the aerator structure is a concrete cascade. It consists of treatment processes such as aeration, coagulation and flocculation unit, sedimentation, filtration, and chlorination structures. The final treated water is lifted via high-lift pumps to a reservoir for the distribution to the town. It served the town for about 20 years and was renovated in 2014 (Sisay et al. 2017).

\section{Sampling of water}

Purposive sampling was used in this study. Water samples were collected using grab sampling into $1 \mathrm{~L}$ of bottles, which were rinsed with ultrapure water and then, the bottles were flushed three times with the water to be sampled. After collection, the samples were labeled and transported to Jimma University Environmental Health laboratory and stored at $4^{\circ} \mathrm{C}$ until further analysis. Before the extraction process, all 
water samples were filtered using Whatman filter paper with a pore size of $8 \mu \mathrm{m}$ to remove any particulate matter.

To assess the fate of pesticide residues during conventional water treatment, from each treatment process three water samples were collected. The samples were collected from the raw water source (Gibe River), aeration effluent, coagulation, and flocculation effluent, sedimentation basin effluent, filtration effluent, and post-chlorination (disinfection) effluent. In total 18 water samples were collected from the conventional water treatment plant, from Jimma southwestern Ethiopia.

To determine the concentration of pesticide residues in the water distribution system of Jimma town, water samples were collected from five water reservoirs, and from each reservoir three water samples, a total of 15 samples were collected which is located in treatment plant compound, Ginjo, Jimma University medical center, Abajifar, and Jiren. And 10 water samples were collected from the community tap,

\section{Effect of water treatment technologies on pesticide residues}

The effect of water treatment technologies on pesticide residues were measured by calculating percent reduction and processing factor.

Pesticides reduction at each water-treatment process were calculated using Equation by (Elfikrie et al. 2020).

Percent reduction $=$

concentration of pesticide in the raw water-concentration of pesticide under treatment $x$ Concentration of pesticide in the raw water

Where $\mathrm{x}$ is treatment process (aeration, coagulation and flocculation, sedimentation, filtration, post chlorination SODIS, and boiling)

OR Percent reduction $=(1-\mathrm{PF}) \star 100$

Percent reduction expressed as percentile. Positive sign of present reduction indicated that reduction factor, whereas negative sign of percent reduction indicated that concentration factor

Processing factor (PF) was calculated as the ratio between the pesticide concentrations in processed water sample $(\mu \mathrm{g} / \mathrm{L})$ to the pesticide concentration in unprocessed water sample $(\mu \mathrm{g} / \mathrm{L})$. PF of $<1$ indicated that there is reduction of pesticides by the processing (reduction factor) whereas, $P F>1$ indicated no reduction by the processing ( $\mathrm{PF}>1$ = concentration factor) 


\section{Processing factor $(\mathrm{PF})=\frac{\text { concentration of processed sample }}{\text { concentration of pesticide in unprocessed(raw) sample }} \ldots$ Equation (2)}

(Mekonen et al. 2015)

\section{Experimental Procedure for Solar Disinfection (SODIS) and boiling as household water treatment methods}

SODIS and boiling was selected as household treatment methods to see if they have an effect on the concentration of pesticides in drinking water. This is because of other treatment mechanism (filtration, sedimentation, and chlorination) were investigated under conventional treatment process. A 1ppm concentration of each pesticides were spiked into distilled water to assess the effect of SODIS and boiling on pesticide level in water. The SODIS intervention was designed according to the Swiss Federal Institute of Aquatic Science and Technology published guideline (Meierhofer and Wegelin 2002) as follow

$\checkmark 1$ liter PET bottle was filled three fourths with sampled water, thoroughly shake the bottles to increase dissolved oxygen, and was filled fully, covered it with an air-tight lid, and placed it horizontally on a reflective corrugated iron sheet. The bottle was exposed to the sun from morning until evening for at least 6 hours.

$\checkmark$ For boiling, water was brought to a rolling point for 1 minute (CDC 2009)

After treatment of spiked distilled water by SODIS and boiling, then extraction procedure was followed using low density based dispersive liquid- liquid micro-extraction.

\section{Chemicals and reagents}

All chemicals and reagents were analytical and HPLC grade. n-hexane (99\%purity), methanol (99\% purity), acetone (99.9\%purity) obtained from biochem pharm, France, and Sodium chloride was used to improves the extraction of analytes due to the salting-out effect. N-hexane was used as extraction solvents. As disperser solvents, acetone was used because it is partially miscible with water. High purity analytical pesticides reference standards ( $\geq 98 \%$ ) such as o'p-DDT, p'p-DDT, p'p-DDD, p'p-DDE lindane, heptachlor, dimethachlor, $\mathrm{y}$-Chlordane, cypermethrin, deltamethrin were used as an analyte for this study.

\section{Preparation of standard solutions}

Stock solutions of $1000 \mathrm{mg} / \mathrm{L}$ for each pesticide were prepared by dissolving accurately weighed $50 \mathrm{mg}$ of each pesticide in a volumetric flask with acetone (except heptachlor, cypermethrin, and deltamethrin which were dissolved in methanol) and stored at $4^{0} \mathrm{C}$. An intermediate solution of $100 \mathrm{mg} / \mathrm{L}$ was prepared by taking $1 \mathrm{ml}$ of stock solution and diluting in $9 \mathrm{ml}$ of the corresponding solvent. Working standard solutions were prepared at concentration ranges of 0.001 to $10 \mathrm{mg} / \mathrm{L}$ by serial dilution of the intermediate solution and then, the solution was stored in the refrigerator at $4{ }^{\circ} \mathrm{C}$. Calibration curves were drawn by running the working standard solutions for each pesticides.

\section{Instruments}


Separation and quantification of the target pesticides were performed using Agilent Gas chromatography equipped with an electron capture detector (GC-ECD), autosampler, pump, and column compartment model 7890A (Agilent technologies, Singapore). An HP-5 capillary column (30 m, 0.25 mm inner diameter; and $0.25-\mathrm{mm}$ film thickness) coated with $5 \%$ phenyl methyl siloxane model $7890 \mathrm{~A}$ was also obtained from Agilent technologies. Other instruments applied were $15 \mathrm{~mL}$ centrifuge tube, analytical balance, $5 \mathrm{~mL}$ syringe, and the centrifuge were used for this study.

\section{Sample extraction procedures}

The low density-based dispersive liquid-liquid microextraction (LD-DLLME) method which was earlier applied by (Dejene et al. 2020) was used with minor modification for extraction of the target pesticide residues from water samples. Accordingly, a $5 \mathrm{~mL}$ water sample was taken into a $15 \mathrm{~mL}$ centrifuge tube and then, a mixture of $100 \mu \mathrm{L} \mathrm{N}$-hexane and $500 \mu \mathrm{L}$ acetone as extraction and disperser solvents respectively were rapidly injected using a $5 \mathrm{~mL}$ medical syringe. Subsequently, after the addition of $0.5 \mathrm{~g}$ $\mathrm{NaCl}$, the content was shaken by hand until the salt was completely dissolved. Then the content was centrifuged for $5 \mathrm{~min}$ at $5000 \mathrm{rpm}$ to facilitate the phase separation. A $50 \mu \mathrm{L}$ of the floating organic phase was carefully withdrawn via a syringe and then transferred into vials. Finally, $1 \mu \mathrm{L}$ of the extract was injected into the Gas chromatography system.

\section{Pesticide identification and quantification}

Analyses of the pesticide residues were performed using GC-ECD. GC-ECD was connected to a nitrogen gas generator of $99.99 \%$ purity used as a carrier and makeup gas. The instrument condition was set by the following conditions. ALS (auto liquid sampler) with $10 \mu \mathrm{L}$ syringes was used and the injection volume was $1 \mu \mathrm{L}$. Splitless injection mode was used with an inlet temperature of $250^{\circ} \mathrm{C}$ and a carrier nitrogen gas flow of $45 \mathrm{ml} / \mathrm{min}$ and a pressure of 10.04 Psi. A column of ( $30 \mathrm{~m} \times 3.20 \mathrm{~mm}$ ) internal diameter and $0.25 \mu \mathrm{m}$ film thickness was used following the oven temperature program with the initial temperature was set at $80^{\circ} \mathrm{C}$, ramp at a rate of $30^{\circ} \mathrm{C} / \mathrm{min}$ to $180^{\circ} \mathrm{C}$, then ramp at a rate of $3^{\circ} \mathrm{C} / \mathrm{min} 205^{\circ} \mathrm{C}$ for $4 \mathrm{~min}$ holding time and then ramp at a rate of $20^{\circ} \mathrm{C} / \mathrm{min} 290^{\circ} \mathrm{C}$ and $8 \mathrm{~min}$ holding time. The total run time was $27.92 \mathrm{~min} . \mu \mathrm{ECD}$ detector temperature was $300^{\circ} \mathrm{C}$ using nitrogen as a makeup gas at a flow rate of $60 \mathrm{ml} / \mathrm{min}$.

\section{Quality control}

All glass wares were washed with solvents before used to remove any contaminants. The quantitative determination of pesticide residue in water was done on the basis of the external standard method. Identification of the pesticides was undertaken by running specific concentrations for each pesticide and by looking at the retention time. And then, the linearity of the standard solutions was measured at five different concentrations of $10 \mathrm{mg} / \mathrm{L}, 1 \mathrm{mg} / \mathrm{L}, 0.1 \mathrm{mg} / \mathrm{L} 0.01 \mathrm{mg} / \mathrm{L}$, and $0.001 \mathrm{mg} / \mathrm{L}$ from the mixture of all standards by their corresponding working concentration. Calibration curves were plotted by taking concentration against the peak area of the individual pesticides and the linearity of the calibration curve 
was validated using a coefficient of determination $\left(r^{2}\right)$. Coefficients of regression $\left(r^{2}\right)$ were greater than 0.995 for all pesticides which indicate that linearity of standard curves.

\section{Statistical analysis}

Excel sheet was used for the calculation of pesticide residues using the equation of the calibration curves. Mean and standard deviation was analyzed using SPSS ${ }^{\circledR} \mathrm{V}, 23$. Shapiro-Wilk was used to check the normality of the data at $P<0.05$ was used. The one-way ANOVA test was used to examine the significant differences (Tukey's test) $(p<0.05)$ for the data which were normally distributed. In contrast Kruskal -Wallis nonparametric test was used for the data which were not normally distributed. $P$-value < 0.05 were considered as significant.

\section{Results And Discussion}

The concentration of pesticides detected in the water samples from Jimma conventional water treatment plants in southwestern, Ethiopia at different processing stages as illustrated in Table 1. The pesticides under study were DDT with its metabolites metabolites ( $p, p^{\prime}-D D E, p, p^{\prime}-D D D, p, p^{\prime}-D D T$ and o, $\left.p^{\prime}-D D T\right)$, heptachlor, $\mathrm{Y}$-Chlordane, lindane, dimethachlor, cypermethrin, and deltamethrin. From our findings, except o'p-DDT all the pesticides under study were detected at the intake point (Gibe River which is the source of water for the treatment plant) of the Jimma conventional treatment plant. This may be due to current or historical illegal use of those banned pesticides or previously used pesticides by farmers could contaminate the source of water. Since this pesticides are highly persistent, the residue may exist for long period of time in the water sources. Farmyard runoff, sewer overflows, and accidental spills (Vryzas 2018) may contribute for the contamination of water in the study area. The mean concentration of $p^{\prime} p^{-D D D}, p^{\prime} p^{-}$ DDE, and p'p-DDT in Gibe River were $70.83 \mu \mathrm{g} / \mathrm{L}, 0.31 \mu \mathrm{g} / \mathrm{L}$, and $158.1 \mu \mathrm{g} / \mathrm{L}$, respectively, this is due to, since Jimma zone in southwest Ethiopia was malaria endemic area these pesticides may be sprayed for public health purpose. The mean concentration of cypermethrin and deltamethrin in Gibe River was 81.78 $\mu \mathrm{g} / \mathrm{L}$ and $28.07 \mu \mathrm{g} / \mathrm{L}$, respectively. This findings were lower relative to a study done in Nigeria by (Akan et al. 2015), mean concentration of p'p-DDD, p'p-DDE, and p'p-DDT in River Water Benue in Vinikilang, Yola, Adamawa State, Nigeria was $2160 \mu \mathrm{g} / \mathrm{L}, 300 \mu \mathrm{g} / \mathrm{L}$, and $3750 \mu \mathrm{g} / \mathrm{L}$ respectively. The concentration of cypermethrin and deltamethrin in River Water Benue in Vinikilang, Yola, Adamawa State, Nigeria was 930 $\mu \mathrm{g} / \mathrm{L}$ and $1140 \mu \mathrm{g} / \mathrm{L}$, respectively. The mean concentration of lindane in the Gibe river of our study area was $1585.45 \mu \mathrm{g} / \mathrm{L}$ which is higher than river water which is located at northern Greece detected at concentration of $0.252 \mu \mathrm{g} / \mathrm{L}$ (Papadakis et al. 2018). This may be due to residence area variation, preferences of users/farmers to different types of pesticides.

The mean concentration of pesticide residue in each processing stage of the conventional water treatment plant is investigated. Kruskal-Wallis test result showed that there is significant difference $(p<$ $0.05)$ in the mean concentration of $p^{\prime} p-D D E$ in raw water $(0.31 \mu \mathrm{g} / \mathrm{L})$ and post chlorination $(2.42 \mu \mathrm{g} / \mathrm{L})$ unit. This is may be due to a reaction between chlorine (post-chlorination) and the chlorinated pesticides. Addition of chlorine can produce the transformation of parent compounds to its metabolites according to 
(Costa et al., 2018). From one way ANOVA test results there is a significant difference $(p<0.05)$ between the mean concentration of raw water $(158.1 \mu \mathrm{g} / \mathrm{L})$ and aeration (ND), coagulation (ND), sedimentation $(18.24 \mu \mathrm{g} / \mathrm{L})$, and filtration unit $(55.31 \mu \mathrm{g} / \mathrm{L})$ for p'p-DDT. This may be due to evaporation, photodecomposition, microorganisms and the hydrophobicity characteristics of this pesticide contribute for the reduction of concentration by the above mentioned water treatment processes

Table 1

Mean concentration $(\mu \mathrm{g} / \mathrm{L})$ of pesticides residue in a different stage of the treatment process

\begin{tabular}{|c|c|c|c|c|c|c|}
\hline \multirow{3}{*}{ Pesticides } & \multicolumn{6}{|l|}{ Mean \pm SD } \\
\hline & $\begin{array}{l}\text { Raw } \\
\text { Water }\end{array}$ & Aeration & $\begin{array}{l}\text { Coagulation } \\
\text { and }\end{array}$ & Sedimentation & Filtration & $\begin{array}{l}\text { Post- } \\
\text { chlorination }\end{array}$ \\
\hline & & & Flocculation & & & \\
\hline p'p-DDD & $\begin{array}{l}70.83 \pm \\
55.49\end{array}$ & $\begin{array}{l}69.27 \pm \\
15.29\end{array}$ & $\begin{array}{l}78.05 \pm \\
49.18\end{array}$ & $\begin{array}{l}107.98 \pm \\
45.15\end{array}$ & $\begin{array}{l}148.81 \pm \\
85.18\end{array}$ & $\begin{array}{l}62.54 \pm \\
6.86\end{array}$ \\
\hline p'p-DDE & $\begin{array}{l}0.31 \pm \\
0.11\end{array}$ & ND & ND & ND & $\begin{array}{l}0.06 \pm \\
0.11\end{array}$ & $\begin{array}{l}2.42 \pm \\
0.34 \star \star\end{array}$ \\
\hline p'p-DDT & $\begin{array}{l}158.10 \pm \\
58.38\end{array}$ & $N D^{*}$ & $N D^{*}$ & $18.24 \pm 0.54 *$ & $\begin{array}{l}55.31 \pm \\
0.43^{\star}\end{array}$ & $\begin{array}{l}75.92 \pm \\
22.80\end{array}$ \\
\hline$y$-Chlordane & $\begin{array}{l}12.21 \pm \\
1.10\end{array}$ & $\begin{array}{l}1.00 \pm \\
0.15\end{array}$ & $1.53 \pm 1.38$ & $3.06 \pm 2.60$ & $\begin{array}{l}3.09 \pm \\
1.58\end{array}$ & $3.11 \pm 1.02$ \\
\hline Dimethachlor & $\begin{array}{l}5510.10 \pm \\
723.41\end{array}$ & $\begin{array}{l}342.83 \pm \\
73.73\end{array}$ & $367 \pm 208.7$ & $\begin{array}{l}6372.45 \pm \\
1249\end{array}$ & $\begin{array}{l}1266.74 \\
\pm 1047.4\end{array}$ & $\begin{array}{l}149.50 \pm \\
127.99 \star \star\end{array}$ \\
\hline Lindane & $\begin{array}{l}1585.45 \pm \\
1337.5\end{array}$ & $\begin{array}{l}809.53 \pm \\
146.8\end{array}$ & $\begin{array}{l}356.17 \pm \\
194.7\end{array}$ & $223.18 \pm 99.3$ & $\begin{array}{l}663.11 \pm \\
405.89\end{array}$ & $\begin{array}{l}135.47 \pm \\
101.27\end{array}$ \\
\hline Heptachlor & $\begin{array}{l}49.28 \pm \\
10.67\end{array}$ & $\begin{array}{l}4.89 \pm \\
2.43\end{array}$ & $\begin{array}{l}42.22 \pm \\
30.95\end{array}$ & $51.78 \pm 5.62$ & $\begin{array}{l}232.87 \pm \\
134.26\end{array}$ & $\begin{array}{l}246.73 \pm \\
196.19\end{array}$ \\
\hline Cypermethrin & $\begin{array}{l}81.78 \pm \\
71.44\end{array}$ & $\begin{array}{l}45.84 \pm \\
0.09\end{array}$ & $81.45 \pm 6.83$ & $76.09 \pm 13.04$ & $\begin{array}{l}59.93 \pm \\
18.28\end{array}$ & $\begin{array}{l}217.39 \pm \\
175.42\end{array}$ \\
\hline Deltamethrin & $\begin{array}{l}28.07 \pm \\
25.94\end{array}$ & $\begin{array}{l}3.18 \pm \\
1.78\end{array}$ & $24.24 \pm 2.90$ & $46.96 \pm 36.83$ & $\begin{array}{l}29.70 \pm \\
6.80\end{array}$ & $\begin{array}{l}31.84 \pm \\
4.35\end{array}$ \\
\hline
\end{tabular}

Note: *represents ANOVA with Tukey post-hoc test results with $P<0.05$ and **represents Kruskal-Wallis test result with $P<0.05, N D=$ Not Detected

The mean concentration of the pesticides under study was analyzed from Jimma water distribution system. Table 2 revealed that, except for o,p'-DDT all studied pesticides are detected. p'p-DDE and p'pDDT were not detected in Jiren and Abajifar reservoirs. Maximum mean concentration of p'p-DDD, p'pDDT, dimethachlor, cypermethrin, and lindane were detected at Gingo and Jimma University medical 
center reservoirs. But the minimum mean concentration of p'p-DDD, p'p-DDE, dimethachlor, lindane, heptachlor, cypermethrin, and deltamethrin was detected in Jiren and Abajifar reservoirs. This indicates most maximum mean concentration of pesticides are detected at Gingo and Jimma University medical center reservoirs, in contrast most minimum mean concentration of pesticides are detected in Jiren and Abajifar reservoirs. The one way ANOVA test results showed that there is a significant difference $(p<$ 0.05) in mean concentration of dimethachlor between Jimma university medical center reservoir and other reservoirs. These all might be due to the location variation of reservoirs, variation in distribution line, and the difference in being near to the different agricultural activities and areas. Jiren and Abajifar reservoirs in Jimma in southwestern, Ethiopia are located in the mountainous area and also there are no agricultural practices near these reservoirs so the residues of pesticide became low. Since Ginjo and Jimma University medical center reservoirs are located at the lowland there might be farmyard runoff and sewer overflows that contribute to the increment of pesticide residue. Reservoir that located at Jimma University medical center has no cover on the top. This may contribute for the contamination of this reservoir with different pesticides coming from different activities.

The mean concentration of $\mathrm{p}, \mathrm{p}^{\prime}-\mathrm{DDE}, \mathrm{p}, \mathrm{p}^{\prime}-\mathrm{DDD}, \mathrm{p}, \mathrm{p}^{\prime}-\mathrm{DDT}$, heptachlor, and lindane in the tap water of our study area were $0.68 \mu \mathrm{g} / \mathrm{L}, 95.91 \mu \mathrm{g} / \mathrm{L}, 55.44 \mu \mathrm{g} / \mathrm{L}, 126.78 \mu \mathrm{g} / \mathrm{L}$, and $126.78 \mu \mathrm{g} / \mathrm{L}$ respective. According to Bulut et al., (2010) in Afyonkarahisar, Turkey the concentration of heptachlor $0.041 \mu \mathrm{g} / \mathrm{L}, \mathrm{DDE} 0.021 \mu \mathrm{g} / \mathrm{L}$, DDD $0.036 \mu \mathrm{g} / \mathrm{L}$. Lindane $(0.03 \mu \mathrm{g} / \mathrm{L})$, heptachlor $(0.02 \mu \mathrm{g} / \mathrm{L})$ and $\mathrm{p}^{\prime} \mathrm{p}-\mathrm{DDT}(0.03 \mu \mathrm{g} / \mathrm{L})$ were detected in Ghana drinking water (Fosu-Mensah et al. 2016a). The mean concentration of cypermethrin and deltamethrin were $179.34 \mu \mathrm{g} / \mathrm{L}$ and $37.78 \mu \mathrm{g} / \mathrm{L}$ in water samples collected from taps. our finding was higher than the study done by (Fosu-Mensah et al. 2016b) in Ghana which is mean concentration of cypermethrin was $0.03 \mu \mathrm{g} / \mathrm{L}$ and the mean concentration of deltamethrin was $0.05 \mu \mathrm{g} / \mathrm{L}$. According to world health organization (WHO) and Netherlands government maximum residue level (MRL) value for total DDT, $\gamma$-Chlordane and lindane is $2 \mu \mathrm{g} / \mathrm{L}, 0.2 \mu \mathrm{g} / \mathrm{L}$ and $2 \mu \mathrm{g} / \mathrm{L}$ respectively, and for Australia the limit is $20 \mu \mathrm{g} / \mathrm{L}$ for total DDT. MRL value for heptachlor is $0.03 \mu \mathrm{g} / \mathrm{L}, 0.3 \mu \mathrm{g} / \mathrm{L}, 0.4 \mu \mathrm{g} / \mathrm{L}$ and $0.04 \mu \mathrm{g} / \mathrm{L}$ according to WHO, Australia, United States of America(USA) and Netherlands guideline respectively (Hamilton et al. 2003). Most pesticides which were detected in water samples from our study areas exceeded the maximum residue limits (MRL) set by this organizations except for $p, p^{\prime}-D D$. The exceedance of MRL confirm that the previous use or continuous illegal use of the pesticide in the study area as both parent and metabolites exceeds the legal limit (MRL). 
Table 2

Pesticide residue concentrations (mean $\pm \mathrm{SD})$ in $(\mu \mathrm{g} / \mathrm{L})$ in Jimma town water distribution system

\begin{tabular}{|c|c|c|c|c|c|c|}
\hline Pesticides & TPR & GR & JUMCR & AR & $J R$ & Tap \\
\hline p'p-DDD & $\begin{array}{l}90.83 \pm \\
58.85\end{array}$ & $\begin{array}{l}128.55 \pm \\
76.26\end{array}$ & $\begin{array}{l}114.24 \pm \\
39.02\end{array}$ & $\begin{array}{l}79.0 \pm \\
33.82\end{array}$ & $\begin{array}{l}63.47 \pm \\
40.66\end{array}$ & $\begin{array}{l}95.91 \pm \\
63.31\end{array}$ \\
\hline p'p-DDE & $\begin{array}{l}0.24 \pm \\
0.01\end{array}$ & $0.43 \pm 0.09$ & $0.25 \pm 0.05$ & $0.1 \pm 40$ & 0.33 & $0.68 \pm 0.65$ \\
\hline p'p-DDT & $\begin{array}{l}3.88 \pm \\
2.49\end{array}$ & $\begin{array}{l}43.05 \pm \\
28.22\end{array}$ & $\begin{array}{l}62.14 \pm \\
39.63\end{array}$ & ND & ND & $\begin{array}{l}55.44 \pm \\
43.22\end{array}$ \\
\hline Y-chlordane & $\begin{array}{l}2.75 \pm \\
2.59\end{array}$ & $3.96 \pm 2.62$ & $4.63 \pm 0.77$ & $3.36 \pm 0.5$ & $9.78 \pm 8.5$ & $3.41 \pm 2.58$ \\
\hline Dimethachlor & $\begin{array}{l}223.63 \pm \\
171.9\end{array}$ & $\begin{array}{l}294.87 \pm \\
157.55\end{array}$ & $\begin{array}{l}1153.55 \pm \\
210.4^{\star}\end{array}$ & $\begin{array}{l}85.47 \pm \\
30.8\end{array}$ & $\begin{array}{l}109.74 \pm \\
1.53\end{array}$ & $\begin{array}{l}359.56 \pm \\
249.27\end{array}$ \\
\hline Lindane & $\begin{array}{l}52.04 \pm \\
23.74\end{array}$ & $\begin{array}{l}180.91 \pm \\
120.35\end{array}$ & $\begin{array}{l}181.04 \pm \\
68.94\end{array}$ & $\begin{array}{l}21.35 \pm \\
1.6\end{array}$ & $\begin{array}{l}42.98 \pm \\
14.43\end{array}$ & $\begin{array}{l}126.97 \pm \\
118.45\end{array}$ \\
\hline Heptachlor & $\begin{array}{l}73.62 \pm \\
12.29\end{array}$ & $\begin{array}{l}96.32 \pm \\
77.67\end{array}$ & $\begin{array}{l}83.77 \pm \\
10.27\end{array}$ & $\begin{array}{l}47.22 \pm \\
2.4\end{array}$ & $\begin{array}{l}50.02 \pm \\
32.9\end{array}$ & $\begin{array}{l}129.78 \pm \\
91.58\end{array}$ \\
\hline Cypermethrin & $\begin{array}{l}98.81 \pm \\
62.66\end{array}$ & $\begin{array}{l}181.22 \pm \\
58.14\end{array}$ & $\begin{array}{l}119.51 \pm \\
85.08\end{array}$ & $\begin{array}{l}131.71 \pm \\
92.35\end{array}$ & $\begin{array}{l}80.28 \pm \\
1.9\end{array}$ & $\begin{array}{l}179.34 \pm \\
161.37\end{array}$ \\
\hline Deltamethrin & $21.14 \pm 10$ & $\begin{array}{l}33.14 \pm \\
14.65\end{array}$ & $34.7 \pm 9.16$ & $\begin{array}{l}22.54 \pm \\
8.66\end{array}$ & $\begin{array}{l}15.75 \pm \\
2.63\end{array}$ & $\begin{array}{l}37.78 \pm \\
21.93\end{array}$ \\
\hline
\end{tabular}

The water treatment process may have an effect on the level of pesticides. According to this study during the aeration process, the concentration of studied pesticides was decreased. The percent reduction ranges from $2.21 \%$ ( $p^{\prime} p-D D D$ ) to $100 \%$ ( $p^{\prime} p-D D E, p^{\prime} p-D D T$ ) by aeration process (Table 3 ). This may be due to evaporation and photodecomposition process which will have a role in loss of pesticide residues. During coagulation and sedimentation, some pesticide residues became more concentrated like dimethachlor, deltamethrin, heptachlor, and p'p-DDD. This may be due to a reaction with chlorine which originates from prechlorination process. There is an addition of chlorine as prechlorination with coagulant in the Jimma water treatment process. Addition of chlorine can result in the reaction of pesticides which will produce the transformation of parent compounds to metabolites (Costa et al. 2018)This may increase the concentration of pesticides during chlorination process or resulted in concentrated pesticide level.

During sedimentation, the percent reduction of pesticides ranged from $88.46 \%$ ( $p^{\prime} p-D D T$ ) to $6.87 \%$ (cypermethrin). Reduction in the concentration of pesticide during coagulation and sedimentation is due 
to the hydrophobic characteristics of organochlorine pesticides. these chemical pesticides preferably bound to the particle phase in the aquatic system then accumulates to the sediment or floc which is supported by a study done by (Akan et al. 2015). According to Ormad et al., (2008)DDT metabolites were degraded around $70 \%$ by the coagulation process, and also $60 \%$ removal was obtained for heptachlor by peroxidation of chlorine. During the filtration process the percent reduction ranges from $80.11 \%$ ( $\left.p^{\prime} p-D D E\right)$ to $26.72 \%$ (cypermethrin). The reason for reducing the concentration of pesticide residues in the filtration processing stage might be due to microorganism that is found in a biological layer on the sand surface and is known as the schmutzdecke might have a role in the reduction of pesticide residues. Pesticides used as mainly microbial nutrient, and ultimately decomposed into some small molecules, such as $\mathrm{CO}_{2}$ and $\mathrm{H}_{2} \mathrm{O}$. The progress is called enzymatic reaction, which included that the compound got into microorganism' body through a certain way firstly, and then through a series of physiological and biochemical reactions under the action of various enzymes, finally pesticide would be completely degraded or broken down into smaller molecular compounds which have non-toxic or less toxic (Huang et al. 2018; El-Gendy et al. 2021). Overall p'p-DDD (11.7\%), p'p-DDT (51.98\%), y-Chlordane (74.55\%), dimethachlor (97.29\%), and lindane (91.46\%) was reduced their concentration through entire treatment process. Even if their concentration decreased, they exceed MRL set by WHO, Australia, USA, and Netherland. While, the concentration of p'p-DDE was below MRL even if the concentration become increased during the entire process. This might be due to the concentration of $p^{\prime} p-D D E$ at the intake point was very low. In another study in Iran the concentration of chlorinated organic pesticides were decreased in most of the conventional water treatment process. However, Metoxychlor were concentrated from raw water in the sedimentation process (Majd et al. 2017).

Table 3

Percentage reduction of pesticide residue (\%) through the conventional water treatment process

\begin{tabular}{|llllll|}
\hline Pesticides & Aeration & $\begin{array}{l}\text { Coagulation \& } \\
\text { flocculation }\end{array}$ & Sedimentation & Filtration & $\begin{array}{l}\text { Post- } \\
\text { chlorination }\end{array}$ \\
\hline p'p-DDD & 2.21 & -10.2 & -52.45 & -110.09 & 11.70 \\
\hline p'p-DDE & 100 & 100 & 100 & 80.11 & -688.28 \\
\hline p'p-DDT & 100 & 100 & 88.46 & 65.02 & 51.98 \\
\hline Y-Chlordane & 93.78 & 87.46 & 74.95 & 74.70 & 74.55 \\
\hline Dimethachlor & 93.78 & 93.34 & -15.65 & 77.01 & 97.29 \\
\hline Lindane & 48.94 & 77.53 & 85.92 & 58.18 & 91.46 \\
\hline Heptachlor & 90.07 & 14.33 & -5.07 & -372.54 & -400.67 \\
\hline $\begin{array}{l}\text { Cypermethrin } \\
\text { Deltamethrin }\end{array}$ & 83.95 & 0.4 & 6.87 & 26.72 & -165.82 \\
\hline $\begin{array}{l}\text { NB; } \text { negative sign indicated that the concentration of pesticides were increase during treatment } \\
\text { process relative to raw water }\end{array}$ & 13.62 & -67.33 & -5.81 & -13.46 \\
\hline
\end{tabular}


The effect of the household water treatment process (boiling and solar disinfection) was investigated by this study. Boiling was not efficient for the removal of p'p-DDD, p'p-DDT, dimethachlor, lindane, heptachlor, cypermethrin, and deltamethrin. This is might be due to, most studied pesticides are chlorinated and are highly thermal resistant (Lozowicka et al. 2016). Only three pesticides concentrations were reduced by boiling treatment process namely; p'p-DDE, o'p-DDT, and $\mathrm{y}$-Chlordane. This may be due to relatively these three pesticides has lower boiling point than the other studied pesticides. O'p-DDT, p'pDDE, and were removed $100 \%, 38.9 \%$, and $27.13 \%$ respectively by boiling process. Boiling point of DDT isomers and $\mathrm{y}$-Chlordane is $260^{\circ} \mathrm{C}$ and $175^{\circ} \mathrm{C}$ respectively. The rest pesticides have a boiling point of in range between $300^{\circ} \mathrm{C}-350^{\circ} \mathrm{C}$.

Using the SODIS treatment, the two pyrethroids (cypermethrin and deltamethrin) were removed by $54.45 \%$ and $15 \%$, respectively. This may be due to photodegradation plays a significant role in the degradation of the product on leaf surfaces and in surface waters especially for pyrethroids (cypermethrin and deltamethrin) according to International Programme on Chemical Safety et al., (1989). $y$-Chlordane, heptachlor, lindane, p'p-DDD, and o'p-DDT were reduced by $44.81 \%, 26.2 \%, 14.45 \%, 5.38 \%$, and $2.31 \%$, respectively (Table 4). 
Table 4

Mean concentration, percentage reduction, and PF of pesticides in the different household water treatment process

\begin{tabular}{|c|c|c|c|c|c|c|c|}
\hline & Untreated & Boiled & & & SODIS & & \\
\hline Pesticides & $\begin{array}{l}\text { Mean } \pm \\
\text { SD }(\mu \mathrm{g} / \mathrm{L})\end{array}$ & $\begin{array}{l}\text { Mean } \pm \\
\text { SD }(\mu \mathrm{g} / \mathrm{L})\end{array}$ & $\begin{array}{l}\text { Percent } \\
\text { reduction } \\
(\%)\end{array}$ & $\mathrm{PF}$ & $\begin{array}{l}\text { Mean } \pm \\
\text { SD } \\
(\mu \mathrm{g} / \mathrm{L})\end{array}$ & $\begin{array}{l}\text { Percent } \\
\text { reduction } \\
(\%)\end{array}$ & PF \\
\hline p'p-DDD & $\begin{array}{l}668.65 \pm \\
134.07\end{array}$ & $\begin{array}{l}863.97 \pm \\
113.53\end{array}$ & -29.21 & 1.29 & $\begin{array}{l}632.68 \pm \\
451.69\end{array}$ & 5.38 & 0.95 \\
\hline p'p-DDE & $\begin{array}{l}14.23 \pm \\
12.39\end{array}$ & $\begin{array}{l}8.69 \pm \\
3.27\end{array}$ & 38.90 & 0.61 & $\begin{array}{l}24.34 \pm \\
12.03\end{array}$ & -71.02 & 1.71 \\
\hline p'p-DDT & $\begin{array}{l}221.41 \pm \\
156.76\end{array}$ & $\begin{array}{l}312.32 \pm \\
254\end{array}$ & -41.06 & 1.41 & $\begin{array}{l}347.35 \pm \\
195.31\end{array}$ & -56.88 & 1.57 \\
\hline o'p-DDT & $\begin{array}{l}89.69 \pm \\
67.47\end{array}$ & ND & 100.00 & 0.00 & $\begin{array}{l}87.62 \pm \\
75.89\end{array}$ & 2.31 & 0.98 \\
\hline Y-Chlordane & $\begin{array}{l}64.46 \pm \\
26.44\end{array}$ & $\begin{array}{l}46.97 \pm \\
34.25\end{array}$ & 27.13 & 0.73 & $\begin{array}{l}35.58 \pm \\
18.8\end{array}$ & 44.81 & 0.55 \\
\hline Dimethachlor & $\begin{array}{l}1096.22 \pm \\
331.13\end{array}$ & $\begin{array}{l}1857 \pm \\
593.35\end{array}$ & -69.42 & 1.69 & $\begin{array}{l}1290.41 \\
\pm 312.42\end{array}$ & -17.71 & 1.18 \\
\hline Lindane & $\begin{array}{l}192.93 \pm \\
38.85\end{array}$ & $\begin{array}{l}457.77 \pm \\
314.83\end{array}$ & -137.27 & 2.37 & $\begin{array}{l}165.05 \pm \\
74.5\end{array}$ & 14.45 & 0.86 \\
\hline Heptachlor & $\begin{array}{l}418 \pm \\
102.11\end{array}$ & $\begin{array}{l}796.92 \pm \\
660.01\end{array}$ & -90.64 & 1.91 & $\begin{array}{l}308.52 \pm \\
161.7\end{array}$ & 26.20 & 0.74 \\
\hline Cypermethrin & $\begin{array}{l}12211 \pm \\
8650.81\end{array}$ & $\begin{array}{l}14428.2 \pm \\
2371\end{array}$ & -18.15 & 1.18 & $\begin{array}{l}5563 \pm \\
380\end{array}$ & 54.45 & 0.46 \\
\hline Deltamethrin & $200 \pm 137$ & $370 \pm 120$ & -85 & 1.85 & $170 \pm 40$ & 15 & 0.85 \\
\hline
\end{tabular}

\section{Conclusions}

Organochlorine pesticides ( $\mathrm{p}, \mathrm{p}^{\prime}-\mathrm{DDE}, \mathrm{p}, \mathrm{p}^{\prime}-\mathrm{DDD}, \mathrm{p}, \mathrm{p}^{\prime}-\mathrm{DDT}$, heptachlor, $\mathrm{Y}$-Chlordane,lindane, and dimethachlor) which were banned for agricultural use and two pyrethroids (cypermethrin and deltamethrin) were detected in Gibe river (intake point), in distribution system and in tap water. The presence of OCP in water samples indicates that there is previous or recent illegal use of pesticides in the study area. Conventional water treatment processes reduce the concentration of $p^{\prime} p^{-D D T}, p^{\prime} p-D D D, Y^{-}$ Chlordane, dimethachlor, and lindane to some extent. However, their concentration still exceeds the MRL set by a different organization. This indicates there were not complete removal of these pesticides through the entire conventional water treatment process. Therefore this may need additional intervention to protect the health of consumers. In addition other alternative pesticides which are less harmful pesticides should be supplied to the farmers and applying other advanced treatment mechanisms to reduce the level of pesticide residues in drinking water is important. The other results indicates that 
pesticides such as $p, p^{\prime}-D D E, p, p^{\prime}-D D D$, and o, $p^{\prime}-D D T$, heptachlor, $\mathrm{y}^{-C h l o r d a n e, ~ l i n d a n e, ~ c y p e r m e t h r i n, ~ a n d ~}$ deltamethrin were reduced through the household water treatment process such as boiling or solar disinfection methods. However, p,p'-DDT, and dimethachlor were not reduced during both household water treatment methods (SODIS and boiling). Other household water treatment method by changing different parameters and SODIS which is not commonly applicable by the public should be recommended to assure the safety of the community. Generally, strict regulation is necessary especially for those pesticides which are not removed by both treatment processes for keeping the people safe and healthy.

\section{Declarations}

\section{Acknowledgements}

We are very much grateful for the administrative support provided by institute of health and department of Environmental Health Science and Technology, Jimma University. Authors also would like to thank our colleagues and workers at treatment plant who assisted us during the laboratory work as well as during the sample collection process from different sampling point.

\section{Ethical Approval}

Not applicable

\section{Consent to Participate}

Not applicable

\section{Consent to Publish}

Not applicable

\section{Authors Contributions}

Temima Jemal and Seblework mekonen contributed starting from the inception of the idea up to the submission of the manuscript, data analysis, and interpretation of results, drafting and editing the manuscript.

Higemengist Astatke designed the method, writing the methodology, chemical analysis, reviewing, and editing of the manuscript.

Amare Terfe contributed in conducting sample collection, laboratory analysis, data entry, data analysis, reviewing and editing of the manuscript.

\section{Funding}

No funding was received for conducting this study. 


\section{Competing Interests}

The authors declare no competing interests.

\section{Availability of data and materials}

Will be available upon the request.

\section{References}

1. Akan JC, Battah N, Waziri M, Mahmud MM (2015) Organochlorine, Organophosphorus and Pyrethroid Pesticides Residues in Water and Sediment Samples from River Benue in Vinikilang, Yola, Adamawa State, Nigeria Using Gas Chromatography-Mass Spectrometry Equipped with Electron Capture Detector. American Journal of Environmental Protection 10

2. Bulut S, Erdoðmup SF, Konuk M, Cemek M (2010) The Organochlorine Pesticide Residues in the Drinking Waters of Afyonkarahisar, Turkey. 9

3. CDC (2009) Fact Sheet for Healthy Drinking Water

4. Chelme-Ayala P, El-Din MG, Smith DW, Adams CD (2011) Oxidation kinetics of two pesticides in natural waters by ozonation and ozone combined with hydrogen peroxide. Water Res 45:2517-2526. https://doi.org/10.1016/j.watres.2011.02.007

5. Costa RO, Barcellos PS, Canela MC (2018) Removal of pesticide residues after simulated water treatment: by-products and acetylcholinesterase inhibition. Eclética Química Journal 43:9

6. Cruz-Alcalde A, Sans C, Esplugas S (2017) Priority pesticides abatement by advanced water technologies: The case of acetamiprid removal by ozonation. Sci Total Environ 599-600:14541461. https://doi.org/10.1016/j.scitotenv.2017.05.065

7. Dejene M, Kedir K, Mekonen S, Gure A (2020) Determination of Selected Pesticide Residues from Gilgel Gibe (I) Hydroelectric Dam Reservoir and Its Tributaries, Jimma Zone, Ethiopia. 16

8. Elfikrie N, Ho YB, Zaidon SZ et al (2020) Occurrence of pesticides in surface water, pesticides removal efficiency in drinking water treatment plant and potential health risk to consumers in Tengi River Basin, Malaysia. Sci Total Environ 712:136540.

https://doi.org/10.1016/j.scitotenv.2020.136540

9. El-Gendy SS, Belal EB, Sidkey NM et al (2021) Monitoring and bioremediation of organochlorine pesticides in surface water with Enterobacter asburiae. Span J Agric Res 18:e0306. https://doi.org/10.5424/sjar/2020184-16794

10. Fosu-Mensah BY, Okoffo ED, Darko G, Gordon C (2016a) Assessment of organochlorine pesticide residues in soils and drinking water sources from cocoa farms in Ghana. SpringerPlus 5:869. https://doi.org/10.1186/s40064-016-2352-9

11. Fosu-Mensah BY, Okoffo ED, Mensah M (2016b) Synthetic Pyrethroids Pesticide Residues in Soils and Drinking Water Sources from Cocoa Farms in Ghana. EP 5:60. 
https://doi.org/10.5539/ep.v5n1p60

12. Hamilton DJ, Ambrus Á, Dieterle RM et al (2003) Regulatory limits for pesticide residues in water (IUPAC Technical Report). Pure and Applied Chemistry 75:1123-1155.

https://doi.org/10.1351/pac200375081123

13. Huang Y, Xiao L, Li F et al (2018) Microbial Degradation of Pesticide Residues and an Emphasis on the Degradation of Cypermethrin and 3-phenoxy Benzoic Acid: A Review. Molecules 23:2313. https://doi.org/10.3390/molecules23092313

14. International Programme on Chemical Safety, UNEP, Weltgesundheitsorganisation, Internationale Arbeitsorganisation (eds) (1989) Cypermethrin. World Health Organization, Geneva

15. Khoshnood M, Azizian S (2012) Adsorption of 2,4-dichlorophenoxyacetic acid pesticide by graphitic carbon nanostructures prepared from biomasses. J Ind Eng Chem 18:1796-1800. https://doi.org/10.1016/j.jiec.2012.04.007

16. Lin L, Xie M, Liang $Y$ et al (2012) Degradation of cypermethrin, malathion and dichlorovos in water and on tea leaves with 03/UV/TiO2 treatment. Food Control 28:374-379. https://doi.org/10.1016/j.foodcont.2012.05.009

17. Loha KM, Lamoree M, de Boer J (2020) Pesticide residue levels in vegetables and surface waters at the Central Rift Valley (CRV) of Ethiopia. Environ Monit Assess 192:546. https://doi.org/10.1007/s10661-020-08452-6

18. Lozowicka B, Jankowska M, Hrynko I, Kaczynski P (2016) Removal of 16 pesticide residues from strawberries by washing with tap and ozone water, ultrasonic cleaning and boiling. Environ Monit Assess 188:51. https://doi.org/10.1007/s10661-015-4850-6

19. Majd SS, Rad MHR, Nazari Z et al (2017) Effect of water treatment process on organochlorine pesticide residue levels in Ahvaz water treatment plant 2. Ukr J Ecol 7:349-352. https://doi.org/10.15421/2017_126

20. Meierhofer R, Wegelin M (2002)SOLAR WATER DISINFECTION A GUIDE FOR THE APPLICATION OF SODIS

21. Mekonen S, Ambelu A, Spanoghe P (2015) Effect of Household Coffee Processing on Pesticide Residues as a Means of Ensuring Consumers' Safety. J Agric Food Chem 63:8568-8573. https://doi.org/10.1021/acs.jafc.5b03327

22. Mekonen S, Argaw R, Simanesew A et al (2016) Pesticide residues in drinking water and associated risk to consumers in Ethiopia. Chemosphere 162:252-260.

https://doi.org/10.1016/j.chemosphere.2016.07.096

23. Mengistie BT, Mol APJ, Oosterveer $P$ (2017) Pesticide use practices among smallholder vegetable farmers in Ethiopian Central Rift Valley. Environ Dev Sustain 19:301-324. https://doi.org/10.1007/s10668-015-9728-9

24. Moussavi G, Hosseini H, Alahabadi A (2013) The investigation of diazinon pesticide removal from contaminated water by adsorption onto NH4Cl-induced activated carbon. Chem Eng J 214:172-179. https://doi.org/10.1016/j.cej.2012.10.034 
25. Ormad MP, Miguel N, Claver A et al (2008) Pesticides removal in the process of drinking water production. Chemosphere 71:97-106. https://doi.org/10.1016/j.chemosphere.2007.10.006

26. Papadakis E-N, Tsaboula A, Vryzas Z et al (2018) Pesticides in the rivers and streams of two river basins in northern Greece. Sci Total Environ 624:732-743. https://doi.org/10.1016/j.scitotenv.2017.12.074

27. Sherpa Awasthi M (2019) Health and Environmental Effects of Organochlorine Pesticides in Developing Countries. OAJESS 2:. https://doi.org/10.32474/OAJESS.2019.02.000135

28. Singh NS, Sharma R, Parween T, Patanjali PK (2018) Pesticide Contamination and Human Health Risk Factor. In: Modern Age Environmental Problems and their Remediation. Springer

29. Sisay T, Beyene A, Alemayehu E (2017) Assessment of Drinking Water Quality and Treatment Plant Efficiency in Southwest Ethiopia. 5

30. Thuy PT, Anh NV, van der Bruggen B (2012) Evaluation of Two Low-Cost-High-Performance Adsorbent Materials in the Waste-to-Product Approach for the Removal of Pesticides from Drinking Water. Clean Soil Air Water 40:246-253. https://doi.org/10.1002/clen.201100209

31. Vryzas Z (2018) Pesticide fate in soil-sediment-water environment in relation to contamination preventing actions. Curr Opin Environ Sci Health 4:5-9. https://doi.org/10.1016/j.coesh.2018.03.001

32. Zhao Q, Ge Y, Zuo P et al (2016) Degradation of Thiamethoxam in aqueous solution by ozonation: Influencing factors, intermediates, degradation mechanism and toxicity assessment. Chemosphere 146:105-112. https://doi.org/10.1016/j.chemosphere.2015.09.009

\section{Figures}




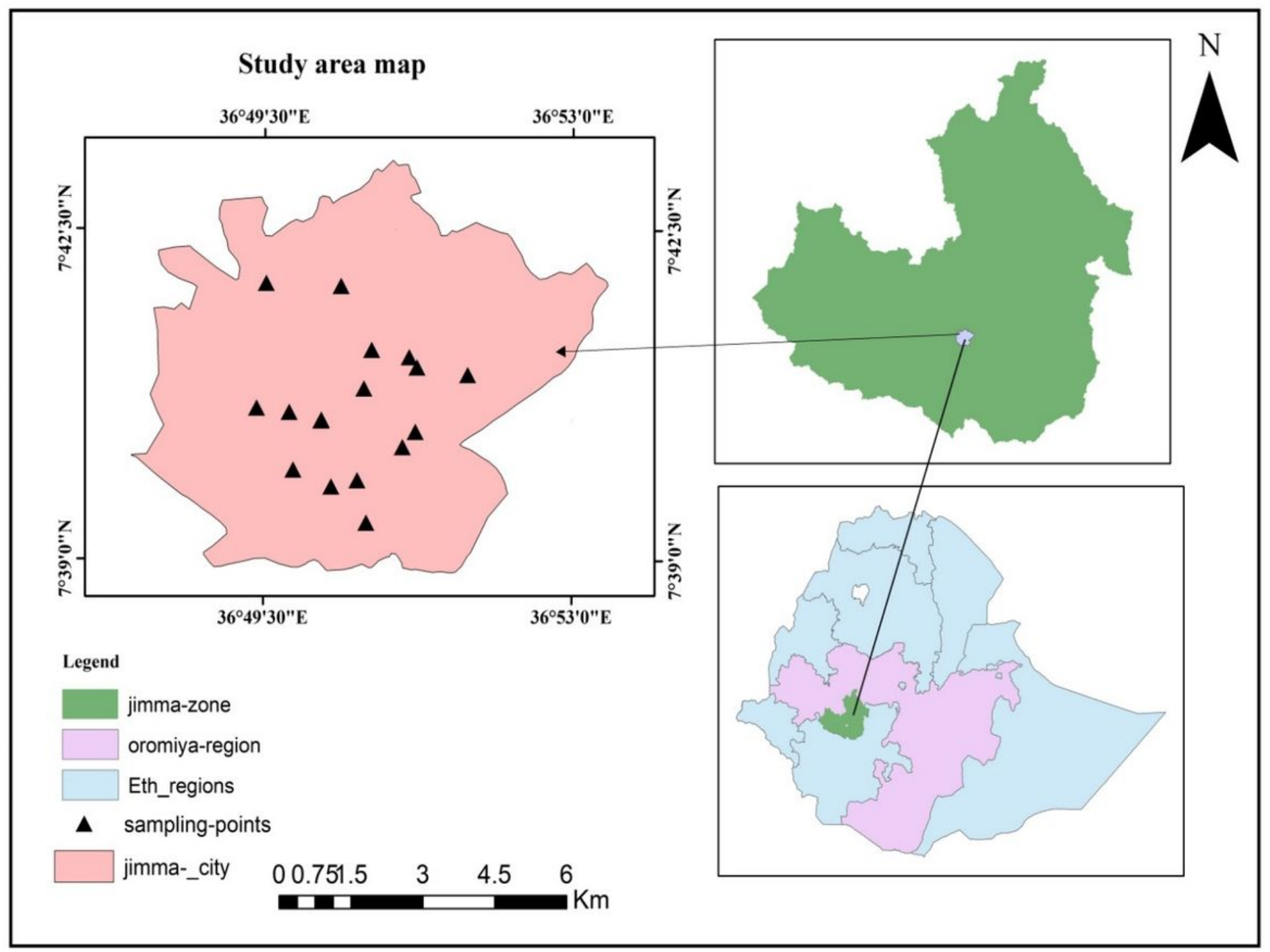

Figure 1

Map of the study area in Jimma town, southwestern Ethiopia 